\title{
EMOTIONAL LANDSCAPE: SOCIO-ENVIRONMENTAL CONFLICT AND PLACE ATTACHMENT. EXPERIENCE FROM THE WIELKOPOLSKA REGION
}

\author{
Francesco PES \\ University of Cagliari, Cagliari, Faculty of Engineering and Architecture, ITALY \\ pes.france@gmail.com
}

Emotional Landscape: Socio-Environmental Conflict and Place Attachment. Experience from the Wielkopolska Region/Iwona MARKUSZEWSKA; Bogucki Wydawnictwo Naukowe, Poznan, 2019, 152 p.

Socio-environmental conflicts and land-use competition are expected to increase in the coming decades due to overpopulation, economic growth and the effects of climate change. In the field of energy production, despite the efforts made to encourage the transition to renewable sources, coal remains one of the most used fossil fuels globally and the most available local source in many countries. The exploitation of mining deposits is a common cause of socio-

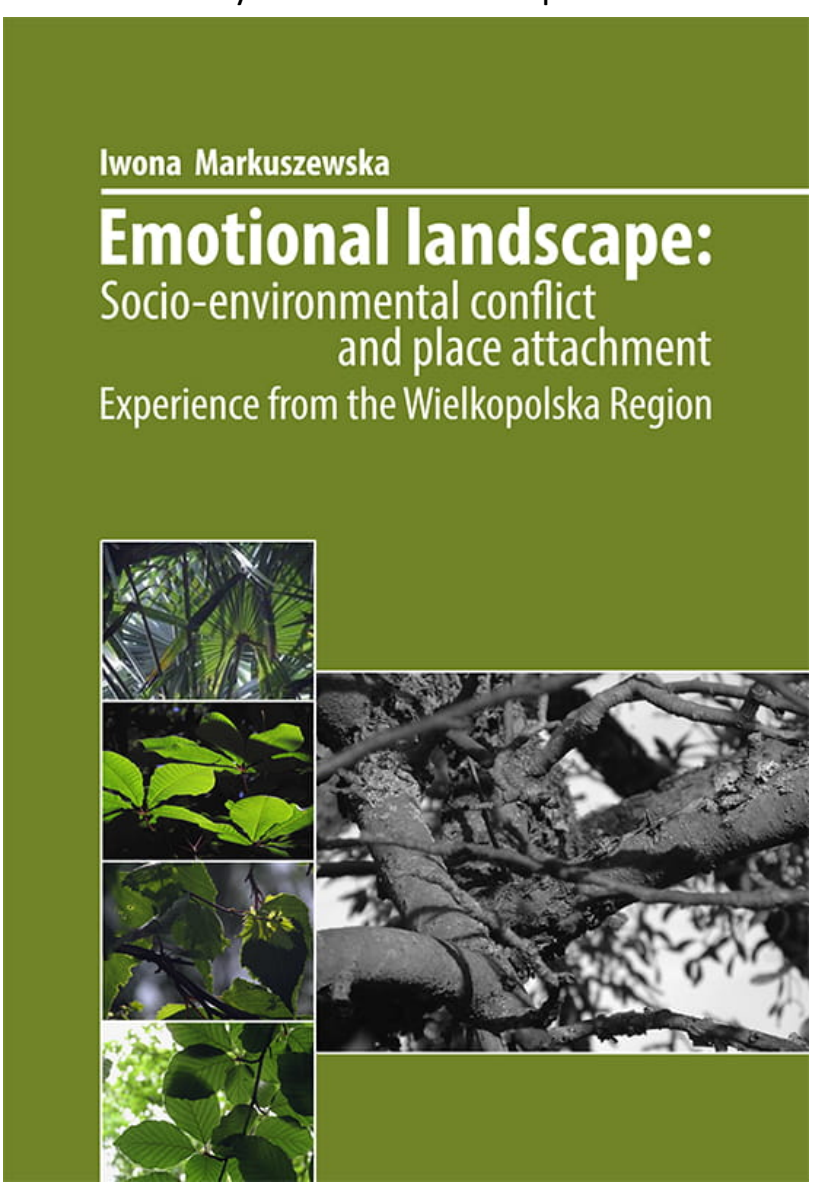
environmental conflict, resulting in high impacts on local habitats, dropping of property values and severe limitations on land use. It is the case of the planned energy investment for the exploitation of the "Oczkowice" lignite deposit, situated on the municipal territory of Krobia and Miesjska Górka in Poland, an area historically characterised by optimal conditions for agricultural production and high concentration of farms.

The 2019 book entitled "Emotional Landscape: Socio-environmental Conflict and Place Attachment. Experience from the Wielkopolska Region" written by Iwona Markuszewska is an interesting and innovative attempt to explore the underlying relationships between place attachment and common attitudes towards critical socio-environmental issues through the lens of emotional geography.

The declared objective of the work consists in finding out the "public 
perception and attitude towards a newly planned surface mining operation of the Oczkowice lignite deposit in the Southern part of the Wielkopolska Region" (Markuszewska, 2019, p. 58). The cause of the conflict has been identified as the land/landscape is at the same time the source of surface soil and underground lignite, in presence of diverse stakeholders interested in the utilisation of different resources.

The book aims to answer the following research questions (Markuszewska, 2019, p. 61): (a) "How do the local residents perceive lignite resources management and the establishment of an open-cast-mine?"; (b) "What kinds of pros and cons are expected due to the implementation of the mining project?"; (c) "What is the interest of the local community in actions taken by antimining lobby groups?"; (d) "What are the bottom-up suggested alternative solutions for sustainable land use management and development?"

After a brief general introduction in the first chapter, Chapter 2 provides an excellent overview of the issues covered in the book, starting with the presentation of the meaning of the term "landscape" in different cultures over the time. This concept is seen through the lens of topophilia and biophilia approaches. Afterwards, the author shows different approaches and meanings deriving from the concept of "space", outlining the main place-related theories and definitions, as place attachment, place identity, place dependence, home attachment, homeland, and home setting. The concept of "socio-environmental conflicts" is analysed through various definitions, as for example conflicts generated by the "emergence of contradictory ideas regarding the management and utilization of diverse natural resources that occupy the same space" (Markuszewska, 2019, p. 47). Then, the author explains the correlation between emotional attitude to a place of residence and NIMBY (Not In My Back Yard) syndrome, also presented as LULU (Locally Unacceptable Land Use) syndrome in socio-environmental conflicts. Finally, the main factors that determine the insurgence of socio-environmental conflicts and several forms of conflict mitigation strategies are explored.

In Chapter 3, the author outlines the research framework used to answer the research questions. To achieve this goal, a mixed quantitative and qualitative methodology has been built. A first quantitative study was conducted between February and May 2016 by means of questionnaires. Then, a qualitative study realised in 2018 through in-depth interviews and informal talks, involved 12 people representing a wide spectrum of local stakeholders. At last, a third study on the topic of place attachment has been accomplished between August and November 2018. This study was realised considering the "three poles of the place attachment model" proposed in Raymond, Brown \& Weber (2010) and consists in the analysis of emotional bonds to a place of living (home), to the community in a place (family and neighbours) and to the surrounding environment (nature) (Markuszewska, 2019, p. 64).

In Chapter 4 the author analyses the spatial area of the Oczkowice lignite deposit, showing the extension of the affected area, the demographic composition and some historical data. The final part of the chapter states the economic and social benefits of the farming practice, with a specific focus on local economic conditions.

In Chapter 5, the first paragraph is dedicated to an overview of global trends in energy production, showing the efforts to reduce energy supply from fossil sources through international and European policies. The author makes some useful considerations about national energy policies in Poland, often based on energy independence and cost-effectiveness criteria, and efforts to foster the use of renewable energy by local municipal authorities. After a brief historical illustration of the emergence of socio-environmental conflict in the case-study area, the outcomes and findings of the three studies are presented and discussed. 
The last Chapter summarises the principal results of the study. At first, the author highlights the reliability of the model in measuring rural dwellers' emotional attachment to their place. Among the key findings, there are the recognition of a strong place attachment and the awareness that the existing bond between farmers and their farmland goes beyond the simple value as a working place in which they make a profit. Another interesting element lies in the fact that the local community opposition to the mining project matches with a higher acceptance of renewable energy solutions that are often considered controversial in different contexts. In conclusion, the main limitation is identified as the context-based nature of this kind of studies, that does not allow generalisation and needs to adjust the research framework depending on local conditions.

The book succeeds in giving a clear picture of the public perception towards the projected mining operation of the Oczkowice lignite over time. A well-structured theoretical framework enables the reader to have a deep comprehension of the issues treated in the case-study; the methodological framework used permits to identify interesting correlations between the different criteria according to participants' profile (age, gender, education, place of residence, pro or anti attitude to the Oczkowice open-pit mine, farming involvement, etc.). Specifically, the study of place attachment, based on Raymond, Brown \& Weber (2010) model conducted through the exploratory factor analysis and Pearson correlation method, has been able to grasp the links of interdependence between the three main components of place attachment (homecommunity-environment). However, a co-construction of the surveys with local communities in the early stage of the research under a participatory process could probably have permitted a higher response rate. Finally, in order to provide answers to the necessity of stronger cooperation among local authorities, stakeholders and policy-makers, a future integration of the proposed methodology within the framework of Ecosystem Services Assessment could be an interesting research line to consider.

\section{REFERENCES}

MARKUSZEWSKA, I. (2019). Emotional Landscape: Socio-environmental Conflict and Place Attachment. Experience from the Wielkoploska Region. Poznan: Bogucki Wydawnictwo Naukowe.

RAYMOND, Ch.M., BROWN, G., \& WEBER, D. (2010). The Measurement of Place Attachment: Personal, Community, and Environmental Connections. Journal of Environmental Psychology, 30, 422-434. 